\title{
Monitoring Konsumsi Listrik Rumah Tangga Berbasis Internet of Things Terintegrasi dengan Virtual Private Server
}

\section{Household Electricity Consumption Monitoring Based Internet of Things Integration with Virtual Private Server}

\author{
I Made Surya Radhitya ${ }^{1}$, Sirojul Hadi ${ }^{2 *}$, Adam Bachtiar ${ }^{3}$ \\ 1,2,3 Universitas Bumigora \\ suryaradhitya98@gmail.com¹, sirojulhadi@universitasbumigora.ac.id ${ }^{2 *}$, \\ adam.bachtiar@universitasbumigora.ac.id ${ }^{3}$
}

\begin{abstract}
Abstrak - Sebagian besar peralatan rumah tangga menggunakan listrik sebagai energinya. Kebutuhan akan listrik dari tahun ke tahun semakin besar. Pengukuran penggunaan daya listrik biasanya dilakukan dengan menggunakan alat ukur sederhana dan pencatatan masih manual sehingga data yang didapat tidak bisa dilakukan setiap saat dan hasilnya terlalu lama untuk didapatkan.Teknologi yang sesuai untuk permasalahan ini yaitu teknologi sistem monitoring daya listrik berbasis Internet of Things (IoT) yang mampu memberikan hasil secara akurat dan real-time. Adapun metode yang dilakukan disusun dalam beberapa tahapan, dimulai dari pengumpulan data, perancangan, konfigurasi, penerapan. Tools yang digunakan dalam penelitian ini akan menggunakan NodeMCU sebagai mikrokontrollernya, sensor arus ACS712 sebagai sensor arus listrik, Virtual Private Server (VPS) sebagai web servernya. Hasil dari penelitian ini yaitu sebuah sistem monitoring daya listrik yang mempermudah memantau daya listrik pada rumah. Akurasi pengukuran daya oleh sistem yaitu 92,87\%. Berdasarkan nilai eror tersebut, maka sistem monitoring konsumsi daya listrik tersebut sudah cukup baik untuk di implementasikan pada rumah.
\end{abstract}

Kata Kunci: Monitoring daya. konsumsi listrik, internet of things, virtual private server

\begin{abstract}
Most household appliances use electricity as their energy. The need for electricity from year to year is getting bigger. Measurement of electrical power usage is usually done using simple measuring instruments and recording is still manual so that the data obtained cannot be done all the time and the results take too long to obtain. The appropriate technology for this problem is the Internet of Things (IoT) based electrical power monitoring system technology. capable of providing accurate and real-time results. The methods carried out are arranged in several stages, starting from data collection, design, configuration, implementation. The tools used in this research will use NodeMCU as the microcontroller, ACS712 current sensor as the electric current sensor, Virtual Private Server (VPS) as the web server. The results of this study are an electrical power monitoring system that makes it easier to monitor electrical power at home. The accuracy of power measurement by the system is 92.87\%. Based on the error value, the electricity consumption monitoring system is good enough to be implemented at home.
\end{abstract}

Keywords: Power monitoring, electricity consumption, internet of things, virtual private server

Jurnal Bumigora Information Technology (BITe)

Vol.3, No.1, Juni 2021, pp. 28-37

ISSN: $2685-4066$

DOI: $10.30812 /$ bite.v3i1.1326 


\section{Pendahuluan}

Listrik merupakan kebutuhan wajib bagi manusia saat ini. Semua peralatan sebagian besar memakai listrik sebagai energinya. Kebutuhan akan listrik dari tahun ke tahun semakin besar, hal ini dikarenakan produsen juga semakin gencar memproduksi berbagai macam peralatan yang fungsinya beragam untuk membantu danmemenuhi kebutuhan manusia, mulai alat-alat elektronik rumah tangga, alat- alat kantor, industri,peralatan olah raga, serta peralatan yang lebih privasi seperti smartphone dan lain sebagainya.

Agar bisa melakukan manajemen listrik yang lebih baik di rumah maka diperlukan suatu perangkat elektronika yang dapat memonitor pemakaian energi listrik pada perangkat yang dianggap cukup boros dengan memanfaatkan mikrokontroler[1]. Pengukuran penggunaan daya listrik biasanya dilakukan dengan menggunakanalat ukur sederhana dan pencatatan masih manual sehingga data yang didapat tidak bisa dilakukan setiap saat dan hasilnya terlalu lama untuk didapatkan[2]. Monitoring ini dilakukan berbasis teknologi Internet of Things (IoT) yang mampu memberikan hasil secara akurat dan real-time dan dapat melakukan komunikasi data melalui jaringan internet[3]. Alat yang digunakan berupa modul nodeMCU ESP8266 sebagai transmitter yang dipadukan dengan sensor[4].

Pada penelitian ini, permasalahan yang ingin diselesaikan yaitu bagaimana pembentukan hubungan dari ruangan atau kamar yang akan dimonitoring dengan user, proses pengiriman data, bagaimana cara mendapat informasi pemakaian nilai daya listrik, teknik penyimpanan data yang di ambil dari ruangan atau kamar yang ingin di monitoring, bentuk penyimpanan data yang telah diambil, bagaimana mengintegrasikan sensor ke internet agar dapat di monitoring saat user tidak berada dirumah dan bagaimana pengolahan datanya saat berada di server dan bentuk penampilan informasi ke user. Harapannya ada sebuah sistem yang dapat memonitoring daya listrik agar user dapat mengetahui pemakaian daya listrik pada setiap ruangan yang berada didalam rumah.

Berdasarkan permasalahan-permasalahanyang telah dijabarkan maka dibangun sebuah sistem yang dapat memonitoring kebutuhan daya listrik pada setiap ruangan atau kamar dalam satu rumah yang terintegrasi dengan sistem Internet of Things (IoT). Perancangan sistem ini menggunakan modul IoT NodeMCU esp8266[5] yang terhubung dengan WIFI sehingga memungkinkan ruangan atau kamar tersebut terhubung ke jaringan internet. Sensor yang digunakan yaitu sensor arus ACS712 yang berfungsi untuk mengukur arus listrik[6]. Sensor sebagai publisher di pasang dibeberapa stop kontak ruangan atau kamar yang akan diukur daya listriknya. Pengiriman data melalui jaringan internet ke virtual private server (VPS) yang aktif sebagai webserver dan kemudian menampilkan data tersebut ke web yang dapat diakses oleh user[7]. Di harapkan penenlitian ini dapat menjadi solusi untuk masyarakat memonitoring daya listrik yang digunakan.

Ada beberapa penelitian terkait seperti yang dilakukan oleh[8], pada penelitian tersebut monitoring daya listrik menggunakan modul PZEM-004T yang berfungsi sebagai sensor arus dan tegangan. Antarmuka monitoring yang digunakan yaitu Cloud Thingspeak. Hasil dari penelitian tersebut yaitu efisiensi pengukuran arus oleh sensor mencapai $100 \%$ dengan error $0 \%$ dan pengukuran tegangan oleh sensor mencapai $99,94 \%$ dengan error $0,06 \%$. Efisiensi mencapai $100 \%$ sangat jarang terjadi pada modul sensor yang beredar di pasaran sehingga perlu ditinjau kembali. Selain itu, penelitian terkait dilakukan oleh [9], pada penelitian tersebut menggunakan sensor arus ina219. Hasil dari penelitian tersebut yaitu error pengukuran arus sebesar 0,02A dan error pengukuran tegangan $0,255 \mathrm{~V}$. Pada penelitian tersebut tidak menampilkan antarmuka IoT yang digunakan. Pada penelitian yang kami lakukan terdapat perbedaan dengan penelitian sebelumnya yaitu sensor yang kami gunakan yaitu ACS712 dan kami mendesain sendiri antarmuka IoT yang digunakan sebagai monitoring konsumsi daya listrik.

Penelitian dilakukan bertujuan untuk dapat mengetahui pemakaian daya listrik pada setiap ruangan atau kamar yang berada didalam rumah. Sehingga user dapat mengetahui daya listrik yang digunakan pada setiap ruangan atau kamar melalui web.

\section{Metode Penelitian}

Pada tahap ini, Langkah-langkah dalam penelitian ini yaitu analisis kebutuhan, perancangan dan implementasi.

https://journal.universitasbumigora.ac.id/index.php/bite

ISSN: 2685-4066 


\subsection{Analisis Kebutuhan}

Analisa kebutuhan digunakan untuk menentukan output atau keluaran yang dihasilkan oleh sistem berdasarkan kebutuhan perangkat lunak (Software) dan kebutuhan perangkat keras(Hardware).

\subsubsection{Kebutuhan Perangkat Lunak}

a. Bahasa pemrograman PHP dan bahasa pemrograman C yang akan diintegrasikanWeb dengan NodeMCU.

b. Putty untuk malakukan remote kepada VPS

c. Menggunakan Template Boostrap AdminLTE sebagai media framework.

d. Menggunakan database MySQL dan Apache.

e. Virtual private server (VPS) sebagai webserver.

f. Kode program ditulis menggunakan media Sublime Text 3 untuk tampilan Web danArduinoIDE untuk memprogram NodeMCU.

\subsubsection{Kebutuhan Perangkat Lunak}
a. Personal Computer (PC) atau Laptop.
b. Mikrokontroler NodeMCU dengan tipe ESP8266 sebanyak dua buah.
c. Sensor arus ACS712 sebanyak 2(dua) buah.
d. Kabel jumper dengan tipe female to female
e. Power Supply (Catu Daya) dengan tegangan5 Volt.
f. WiFi Router

\subsection{Diagram Blok Sistem Monitoring}

Diagram blok tersebut menunjukkan alur kerja dari sistem monitoring daya listrik secara keseluruhan. NodeMCU akan memproses data yangtelah diterima dari sensor arus ACS712. Setelah data tersebut di proses, data tersebut akan dikirimkan ke database pada virtual private server (VPS) dan akanditampilkan ke bentuk tampilan web, sehingga memudahkan dalam membaca data dalam bentuk grafis daripada berbentuk hanya tulisan pada tampilan database. Diagram blok dari sistem monitoring tersebut dapat ditunjukkan pada Gambar 1.

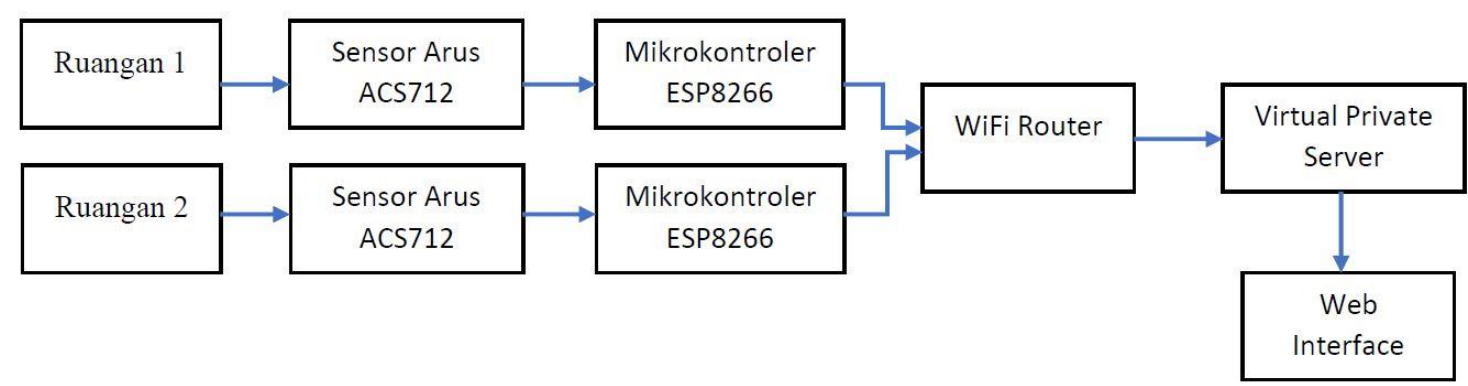

Gambar 1 Diagram blok sistem keseluruhan.

\subsection{Desain Perangkat Keras}

Rancangan perangkat keras yang akan digunakan untuk membangun sistem monitoring daya listrik. Pada Gambar 2 terlihatjuga ada 6 perangkat keras yang digunakan. Internetdan VPS, bukan perangkat keras, karena internetmerupakan seluruh jaringan komputer yang terhubung serta VPS merupakan tempat yang melayani penyewaan menyimpan data website. Perangkat keras tersebut digolongkan berdasarkan tempat perangkat keras itu berada, yaitu lokal dan publik. 


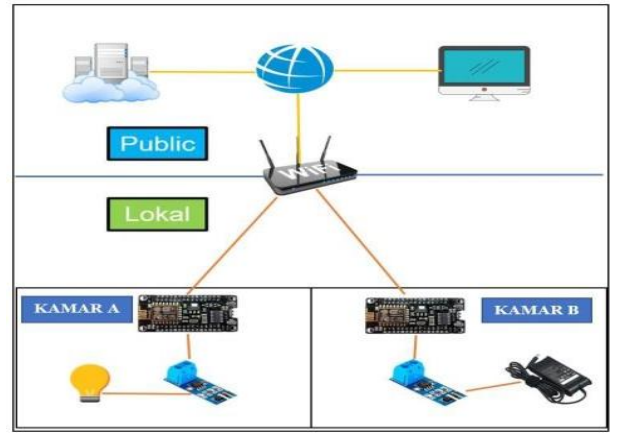

Gambar 2 Diagram blok perangkat keras dan perangkat lunak.

\subsubsection{NodeMCU ESP8266}

NodeMCU digunakan sebagai pusat pemrosesan data, seperti penerimaan data dari sensor, penerjemahan data dari sinyal analog ke digital maupun sebaliknya, memberikan perintah seperti penerima serta pengirim data ke VPS. Penggunaan nodeMCU ESP8266 banyak digunakan pada sistemsistem yang mengimplementasikan internet of things pada sistem yang dibangun[10].

\subsubsection{Sensor Arus ACS712}

Sensor arus ACS712 digunakan untuk mengukur arus listrik. Sensor arus pada penelitian ini digunakan untuk mengukur arus listrik pada Kamar A dan Kamar B yang sebagai mediapengukuran daya listrik.

\subsubsection{WiFi Router}

Wifi router digunakan untuk perantara pengiriman data dari nodeMCU dan VPS. Jadi perangkat nodeMCU akan terhubung dengan WiFi.

\subsubsection{Beban Listrik}

Beban listrik yang digunakan untuk lampu dan charger laptop sebagai beban listrik pada masingmasing ruangan atau kamar yang berada dalam rumah.

\subsection{Perancangan Perangkat Lunak}

Pada pengembangan sistem monitoring dayalistrik juga menggunakan perangkat lunak. Sistem ini menggunakan database yang berjalan di VPS serta bahasa pemrograman PHP untuk membuat website dan bahasa pemrograman $\mathrm{C}$ untuk memprogram NodeMCU.

\subsubsection{Desain Database}

Database yang digunakan pada pengembangan monitoring daya listrik inimenggunakan MySQL. Pada rancangan database akan digunakan dua buah tabel master untuk membangun sistem monitoring daya listrik.

Tabel 1 Database pada Kamar A

\begin{tabular}{ccccc}
\hline No & Nama Atribut & Tipe & Size & Keterangan \\
\hline 1 & no(*) & Integer & 10 & Identitas data \\
2 & Watt & Integer & 10 & Data sensor arus \\
3 & Time & Integer & - & Waktu data dimasukan \\
\hline
\end{tabular}

Tabel 2 Database pada Kamar B

\begin{tabular}{ccccc}
\hline No & Nama Atribut & Tipe & Size & Keterangan \\
\hline 1 & no(*) & Integer & 10 & Identitas data \\
2 & Watt & Integer & 10 & Data sensor arus \\
3 & Time & Timestamp & - & Waktu data dimasukan \\
\hline
\end{tabular}


Pada Tabel 1 dan Tabel 2 digunakan untuk menampung semua data dari sensor arus ACS712. Data pada tabel tersebut dikirimkan oleh nodeMCU ESP8266 yang telah terpasang pada masing-masing kamar.

\subsubsection{Desain Antarmuka Web}

Antarmuka web diperlukan untuk melihat parameter-parameter yang telah dilaporkan oleh masing-masing sensor melalui NodeMCU ke database. Sehingga data-data parameter tersebut yang ditampilkan ke bentuk antar muka web. Adapun desain awal antarmuka web dapat ditunjukkan pada Gambar 3.

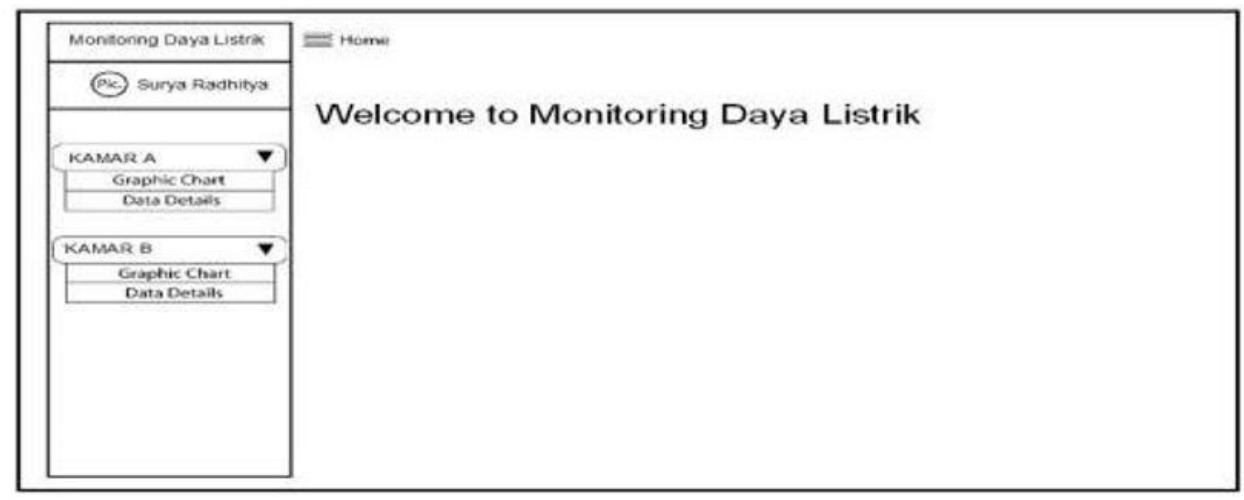

Gambar 3 Antarmuka Web.

Tampilan dari halaman utama web monitoring yang akan diimplementasikan. Pada tampilan tersebut akan terbagi dalam 2 (dua) buah menu dan 4 (empat) buah sub-menu yang masing- masing memiliki tugas menampilkan data-data pada database yang telah diterima oleh VPS. Menu-menu tersebut meliputi "KAMAR A" dan "KAMAR B".

\subsubsection{Instalasi dan Konfigurasi VPS}

Pada tahap ini dilakukan konfigurasi VPS yang berfungsi sebagai webserver yangmenggunakan webpanel VestaCP pada vps agar memudahkan didalam mengelola paket-paket program yang ada pada VPS yang akan digunakanoleh peneliti.

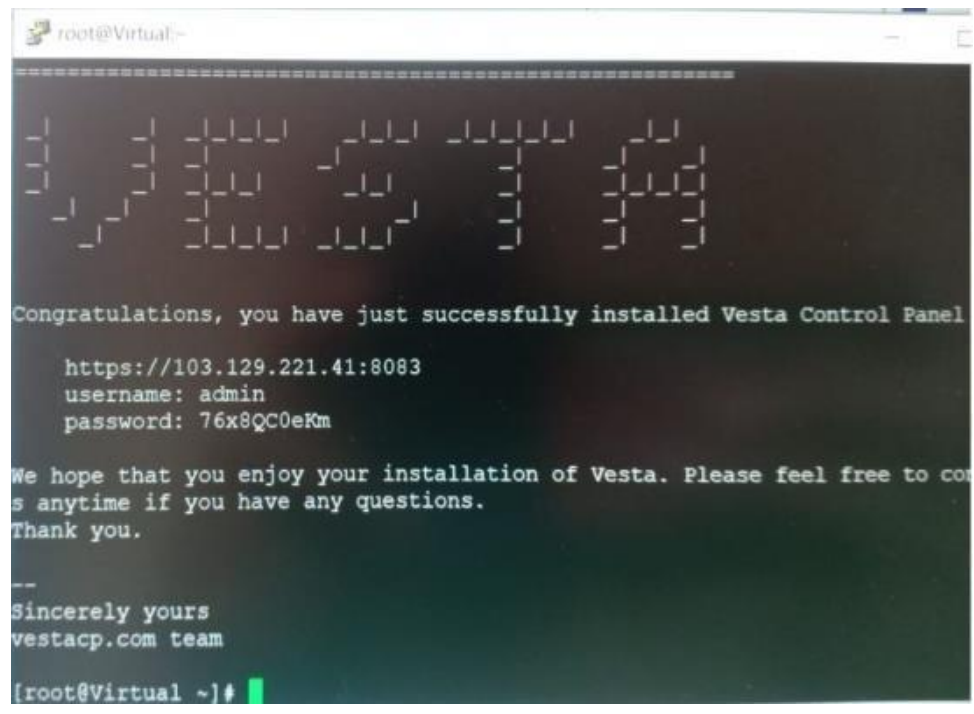

Gambar 4 Hasil instalasi VestaCP pada VPS

https://journal.universitasbumigora.ac.id/index.php/bite

ISSN: 2685-4066 


\section{Hasil dan Pembahasan}

\subsection{Hasil Perancangan Alat}

Rancangan yang telah direncanakan bab sebelumnya pada tahap desain perangkat keras. Berikut merupakan hasil perancangan perangkat keras dari sistem monitoring daya seperti ditunjukkan pada Gambar 5.

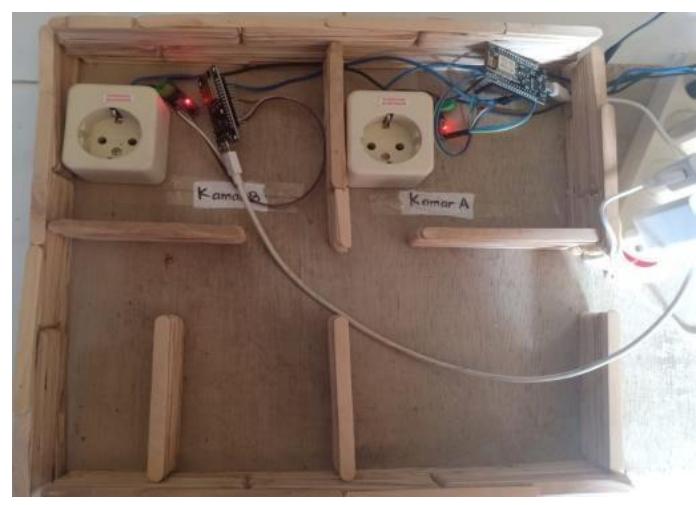

Gambar 5 Hasil perancangan perangkat keras.

\subsection{Pengujian Pengiriman Data}

Data yang telah dibaca dan diproses oleh nodeMCU dari sensor ACS712 pada kamar A dan kamar B dikirimkan ke database Virtual Private Server (VPS) dalam bentuk angka yang akan ditampilkan dalam bentuk antarmuka web.

Tabel 3 Pengiriman data dari nodeMCU ESP8266 ke VPS.

\begin{tabular}{|c|c|c|c|c|c|}
\hline No & Fitur & Param & Metode & Response & Keterangan \\
\hline 1 & $\begin{array}{l}\text { Sensor } \\
\text { Kamar A }\end{array}$ & sensorValue $=16$ & GET & $\begin{array}{l}\text { Data Kamar A } \\
\text { Berhasil Masuk }\end{array}$ & Berhasil \\
\hline 2 & $\begin{array}{l}\text { Sensor } \\
\text { Kamar B }\end{array}$ & nilai_sensor2=32 & GET & $\begin{array}{l}\text { Data Kamar B } \\
\text { Berhasil Masuk }\end{array}$ & Berhasil \\
\hline
\end{tabular}

Sensor kamar A dapat di akses pada alamat URL http://online.suryaradhitya.com/add.php dan sensor kamar B dapat di akses pada alamat URL http://online.suryaradhitya.com/add2.php seperti ditunjukkan pada Tabel 3.

Perangkat dari NodeMCU mengirimkan data melalui perantara WiFi Router, dengan mengakses alamat website (URL) yang telah ada dalam program. Setelah itu URL tersebut ditambahkan parameter data sensor untuk dimasukkan ke dalam masing-masing tabel pada database.

\subsection{Pengujian Web Monitoring}

Pengujian ini dilakukan pada tanggal 7Februari 2020. Pengujian tersebut akan menampilkan data hasil pembacaan 2 (dua) buah sensor yaitu sensor pada kamar A dan kamar B akan ditampilkan dalam website yang telah persiapkan dan telah diuji pada langkah sebelumnya. Hasil tersebut dapat diakses melalui perangkat elektronik apa saja dengan syarat memiliki web browser dan konektivitas internet. Antarmuka ini akan muncul ketika mengakses alamat website:http://online.suryaradhitya.com/

Perangkat yang digunakan untuk uji coba web monitoring pada tanggal 7 februari dengan menggunakan 1 (satu) buah lampu pada kamar A dan kipas angin pada kamar B, kemudian yang akan di tukar setiap menitnya selama 5 (lima) menit untuk mencoba pengujian web monitoring. 


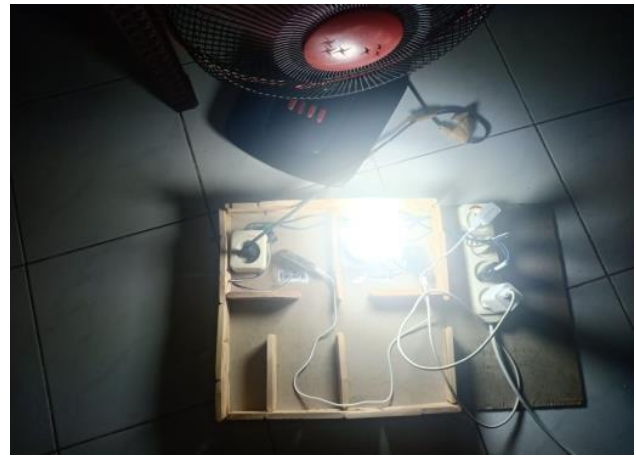

Gambar 6 Pengujian daya listrik dengan beban kipas dan lampu

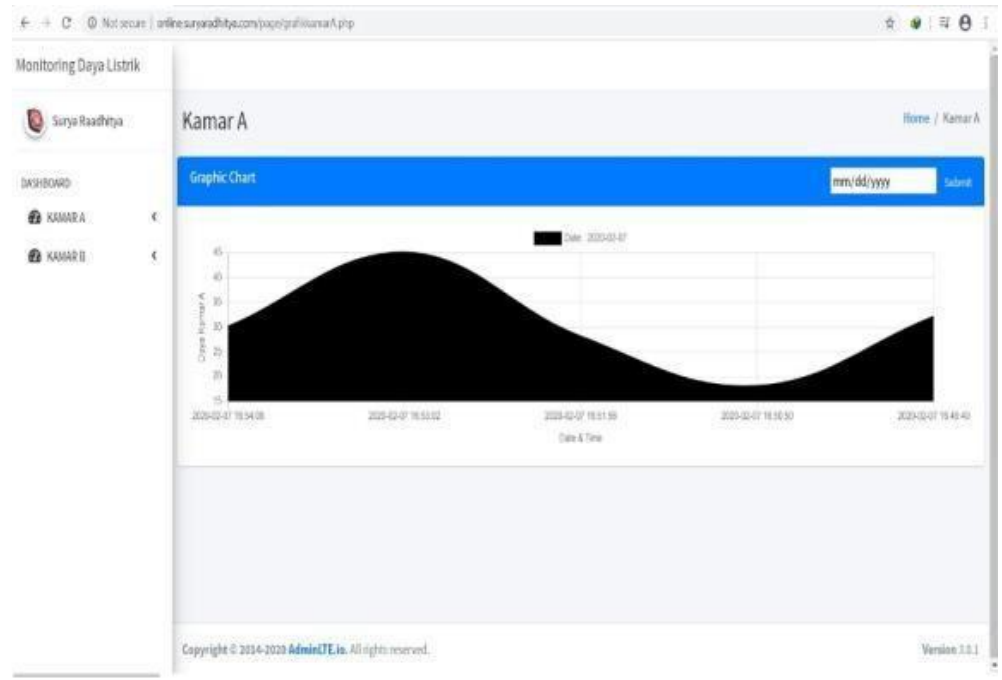

Gambar 7 Tampilan grafik beban pada kamar A.

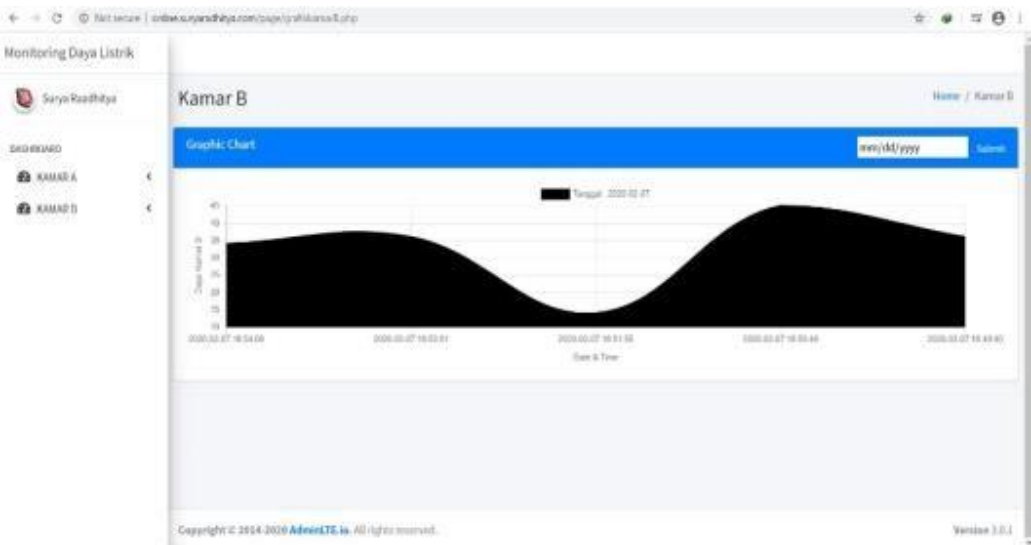

Gambar 8 Tampilan grafik beban pada kamar B

Pada Gambar 7 dan Gambar 8 menunjukan hasil dari data sensor kamar A dan kamar B dalam bentuk grafik. Rangkaian elektronika dimulai selama 5 (lima) menit, data yang di perolehsebanyak lima data yang nilai daya listriknya berubah-ubah tiap menitnya, bahwa perangkat bekerja dengan baik. 


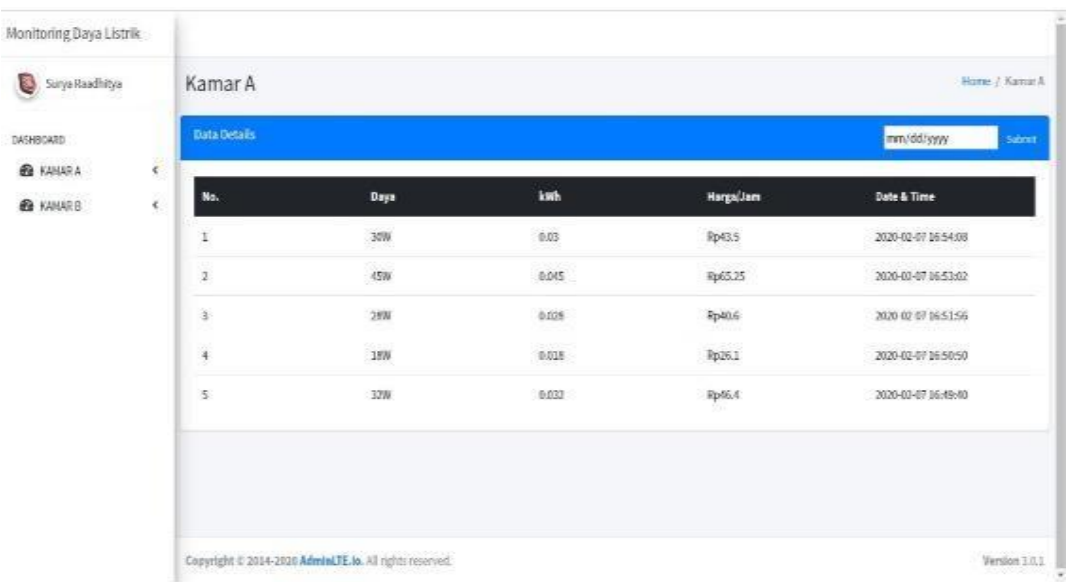

Gambar 9 Tampilan data sensor kamar A dalam bentuk tabel.

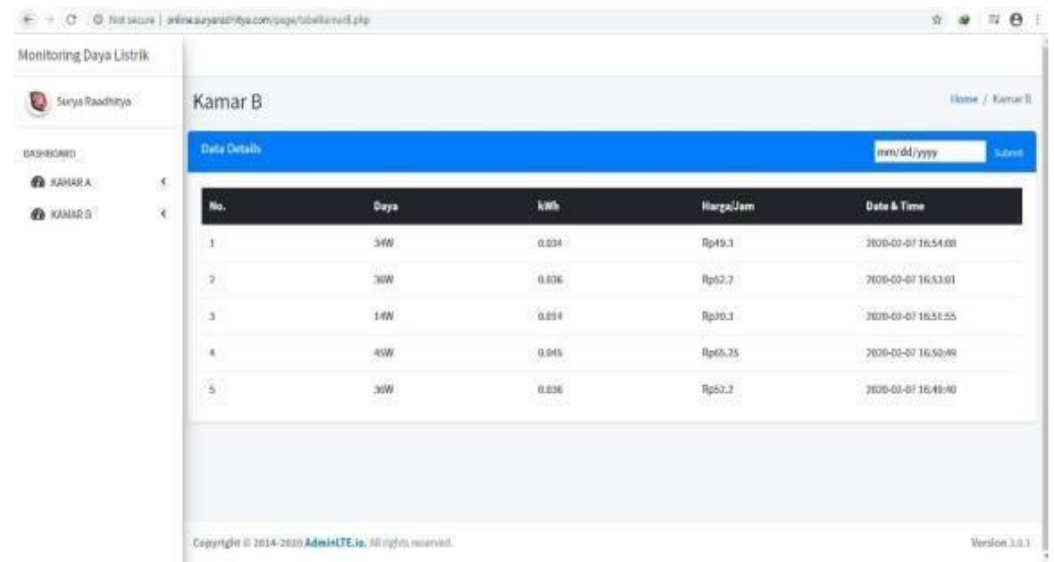

Gambar 10 Tampilan data sensor kamar B dalam bentuk tabel

Pada Gambar 8 dan Gambar 9 menunjukan data tabel selama pengujian yang telah dilakukan, pada tabel tersebut pengguna tidak hanya dapat melihat berapa daya dari kamar A dan kamar B, Pengguna juga dapat melihat berapa $\mathrm{kWh}$ dari daya tersebut dan berapa harga perjam jika daya listrik itu digunakan selama satu jam.

\subsection{Pengujian Sistem Keseluruhan}

Pengujian akurasi monitoring perangkat keras dilakukan untuk menguji keakuratan hasil pengukuran arus listrik yang dilakukan oleh sensor arus ACS712 dengan NodeNCU ESP8266 yang terpasang pada terminal listrik di kamar A dan kamar B. Hasil perhitungan daya listrik yang didapat juga akan diukur akurasinya. Pengujian ini dilakukan pada dua kamar dengan perangkat elektronik terpasang pada terminal listrik yang berbeda-beda. Sedangkan hasil pengujian didapat dengan membandingkan hasil pengukuran aruspada perangkat keras dan tegangan serta daya listrikyang dihitung dengan menggunakan alat Clamp Meter. 


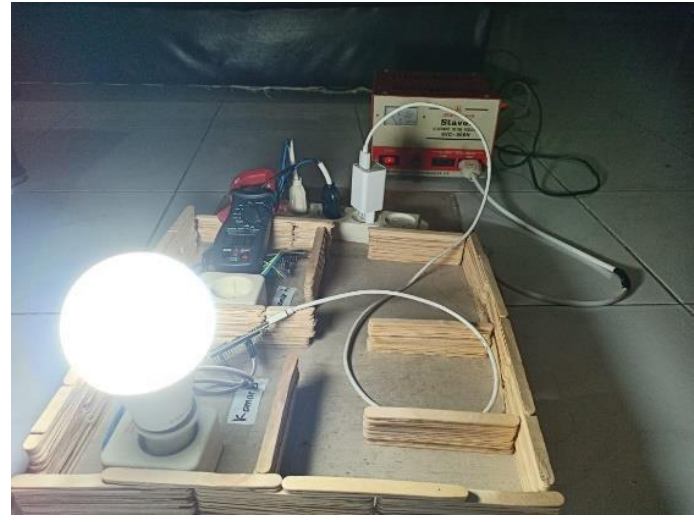

Gambar 11 Pengujian sensor arus ACS712 dan clamp meter

Pada Gambar 11 menunjukan pengujian beban pada kamar A dan kamar B. pertama pengujian dilakukan pada kamar B menggunakan clamp meter dan sensor arus ACS712 yang telah terhubung ke sistem monitoring. Beban yang digunakan yaitu 1 (satu) buah lampu dan kipas angin. Kemudian pengujian seperti ini juga dilakukan pada kamar A untuk mengukur arus dari kamar A menggunakan clamp meter, tetapi perangkat elektronik yang digunakan pada kamar A untuk pengujian sensor arus berbeda yaitu 2 (dua) buah lampu. Hasil pengujian sistem monitoring dapat ditunjukan pada Tabel 4.

Tabel 4 Hasil pengujian beban pada kamar A dan kamar B

\begin{tabular}{ccccccccc}
\hline No & Kamar & \multicolumn{4}{c}{ Sistem Monitoring Daya } & \multicolumn{4}{c}{ Clamp Meter } \\
& & I & V & P & I & V & P & P $(\%)$ \\
\hline 1 & A & 0,30 & 220 & 66 & 0,32 & 220 & 70,4 & $93,75 \%$ \\
2 & B & 0,21 & 220 & 55 & 0,23 & 220 & 50,6 & $92 \%$ \\
\hline
\end{tabular}

Keterangan:

$\mathrm{I}=$ Arus, $\mathrm{V}=$ Tegangan, $\mathrm{P}=$ Daya

Tabel 4 menunjukan hasil pengukuran arus, tegangan, dan daya listrik. Hasil yang di dapatkan yaitu daya listrik yang terukur memiliki nilai rata-rata 92,87\%. Perbedaan tersebut juga dapat diakibatkan oleh noise yang terjadi pada proses sampling sinyal analog sensor arus listrik ke dalam bentuk nilai angka atau dari penggunaan komponen atau penyusunan rangkaian elektronik dari perangkat keras monitoring listrik yang kurang baik. Untuk nilai tegangan listrik yang dibaca oleh clamp meter berada tepat pada nilai tegangan sebesar 220V. Pengguna harus menggunakan Stavolt untuk membuat tegangan listrik stabil agar memiliki parameter yang sesuai dengan sistem yang telah dibuat agar memiliki nilai default $220 \mathrm{~V}$ pada tegangan listrik.

\section{Kesimpulan}

Berdasarkan hasil pengujian sistem maka kesimpulan yang dapat diambil berdasarkan hasil instalasi, konfigurasi dan analisa ujicoba yaitu sistem ini dapat memberikan kemudahan bagi pengguna untuk memantau konsumsi daya yang digunakan pada ruangan atau kamar di sebuah dari jarak jauh. Sistem ini dapat bekerja apabila terdapat sinyal WiFi dan kelancaran sistem ini tergantung dari kuat sinyal WiFi yang diterima oleh alat. Sistem monitoring daya listrik telah berhasil dibangun dengan integrasi sensor ACS712. Halini dibuktikan dengan pengujian sistem monitoring daya listrik dengan tingkat akurasi 92,87\%. Adapun hal yang perlu di tingkatkan dalam penelitian ini yaitu menambah tingkat akurasi sensor sehingga lebih baik dengan melakukan kalibrasi pada program.

\section{Ucapan Terima Kasih}

Terima kasih disampaikan kepada Tim Jurnal BITe yang telah memberikan kesempatan untuk kami untuk mempublikasikan penelitian kami. 


\section{Referensi}

[1] T. Nusa, S. R. U. A. Sompie, and E. M. Rumbayan, "Sistem Monitoring Konsumsi Energi Listrik Secara Real Time Berbasis Mikrokontroler," E-Journal Teknik Elektro Dan Komputer, vol. 4, no. 5, pp. 19-26, 2015, doi: 10.35793/jtek.4.5.2015.9974.

[2] D. Handarly and J. Lianda, "Sistem Monitoring Daya Listrik Berbasis IoT (Internet of Thing)," JEECAE (Journal of Electrical, Electronics, Control, and Automotive Engineering), vol. 3, no. 2, pp. 205-208, 2018, doi: 10.32486/jeecae.v3i2.241.

[3] P. A. Wulandari, P. Rahima, and S. Hadi, "Rancang Bangun Sistem Penyiraman Otomatis Berbasis Internet of Things Pada Tanaman Hias Sirih Gading," Jurnal Bumigora Information Technology (BITe), vol. 2, no. 2, pp. 77-85, 2020, doi: 10.30812/bite.v2i2.886.

[4] U. Ulumuddin, M. Sudrajat, T. D. Rachmildha, N. Ismail, and E. A. Z. Hamidi, "Prototipe Sistem Monitoring Air Pada Tangki Berbasis Internet of Things Menggunakan Nodemcu Esp8266 Sensor dan Ultrasonik," Seminar Nasional Teknik Elektro 2017, no. 2016, pp. 100105, 2017, doi: 978-602-512-810-3.

[5] E. S. I. Team, "ESP8266EX Datasheet," 2015. [Online]. Available: https://www.adafruit.com/images/product-files/2471/0A-ESP8266_Datasheet_EN_v4.3.pdf.

[6] A. MicroSystems, "Datasheet ACS712," 2006. [Online]. Available: https://www.alldatasheet.com/datasheet-pdf/pdf/174116/ALLEGRO/ACS712.html.

[7] A. Almurayh, "Virtual Private Server," Spring, p. 28, 2010.

[8] H. B. Santoso, S. Prajogo, and S. P. Mursid, "Pengembangan Sistem Pemantauan Konsumsi Energi Rumah Tangga Berbasis Internet of Things (IoT)," ELKOMIKA: Jurnal Teknik Energi Elektrik, Teknik Telekomunikasi, \& Teknik Elektronika, vol. 6, no. 3, p. 357, 2018, doi: 10.26760/elkomika.v6i3.357.

[9] Tukadi, W. Widodo, M. Ruswiensari, and A. Qomar, "Monitoring Pemakaian Daya Listrik Secara Realtime Berbasis Internet of Things," Seminar Nasional Sains dan Teknologi Terapan VII 2019, pp. 581-586, 2018.

[10] A. Heryanto, J. Budiarto, and S. Hadi, "Sistem Nutrisi Tanaman Hidroponik Berbasis Internet Of Things Menggunakan NodeMCU ESP8266," Jurnal Bumigora Information Technology (BITe), vol. 2, no. 1, pp. 31-39, 2020, doi: 10.30812/bite.v2i1.805. 